\title{
QUALITATIVE MODELLING IN EMBODIMENT DESIGN - INVESTIGATING THE CONTACT AND CHANNEL APPROACH THROUGH ANALYSIS OF PROJECTS
}

\author{
P. Grauberger $\bowtie$, F. Bremer, C. Sturm, K. Hoelz, H. Wessels, T. Gwosch, R. Wagner, \\ G. Lanza, A. Albers and S. Matthiesen \\ Karlsruhe Institute of Technology, Germany \\ $\triangle$ patric.grauberger@kit.edu
}

\begin{abstract}
Purposeful qualitative modelling of embodiment function relations is a challenge in embodiment design. This contribution investigates the applicability and usefulness of the Contact and Channel Approach as a qualitative modelling approach in a survey study. From 23 development and research projects, advantages and challenges regarding applicability and usefulness are identified. A further result is that many different models are used additionally to the Contact and Channel Approach. Based on the findings, research potential for optimization and development of links to other models emerges.
\end{abstract}

Keywords: engineering design, design models, design research, embodiment design, contact and channel approach

\section{Introduction}

Model building facilitates the reduction of complexity in real systems in order to make them manageable (Stachowiak, 1973). Explication of product models supports the development of new solutions by assisting the recognition of correlations and making them visible to others (Buur and Andreasen, 1989; Kohn, 2014). Several different models are used to model technical systems in different degrees of abstraction (Ehrlenspiel and Meerkamm, 2017). Models can be created and combined with the help of different analysis methods and model building techniques. A challenge in product development is that it is often not clear which models exist and which of them should be used or combined to get the desired results (Matthiesen et al., 2019a). In embodiment design, the joint modelling of aspects of embodiment and function is necessary as the products embodiment has to be designed according to its functional requirements (Matthiesen, 2011). For modelling embodiment function relations (EFRs), qualitative and quantitative models exist.

Quantitative models are often implemented into commercial tools (e.g. multibody simulations or finite element models). They are based on parameterised product models and are developed and investigated by researchers as well as companies developing their software implementations (Haefner and Lanza, 2017; Wagner et al., 2018). Modelling approaches like Axiomatic Design (Suh, 1998), Design Structure Matrices (Yassine and Braha, 2003), or the Characteristics Properties Modelling (CPM) (Weber, 2014) are not necessarily software-based, however still need parameterised product definitions as basis. Modelling approaches like the Organ Domain Models (Andreasen et al., 2015) or the Contact and Channel Approach (C\&C2-Approach) (Albers and Matthiesen, 2002; Matthiesen, 2020) do not need a 
parameterised product definition and can be used in early phases of product development. To improve these models through research, investigations of their application are needed.

Focus of research regarding the $\mathrm{C} \& \mathrm{C}^{2}$-Approach is up to now either very detailed, where one or few investigations are conducted in detail, or summarizing on an abstract level. In the detailed investigations it is often difficult to generalise findings as they are system specific. For example, the investigation of a sunroof system shows challenges in modelling state-dependent EFRs, however it remains unclear if these challenges emerge in other systems as well (Matthiesen et al., 2019b). In the summarizing analyses, the data are often not detailed enough to derive specific research potential. For example, an investigation of publications was conducted to find out how far and to what purpose the $\mathrm{C} \& \mathrm{C}^{2}$-Approach is being used (Grauberger et al., 2019). From this investigation, insights about general purposes of the approach and its appliance in the community could be derived, however it became clear that more detailed research into projects underlying the publications is needed to identify detailed research potential of the $\mathrm{C} \& \mathrm{C}^{2}$-Approach regarding its usefulness and applicability.

In this contribution, projects using the $C \& C^{2}$-Approach are investigated to identify advantages and challenges as basis for further development of the approach. Based on a similar investigation of the

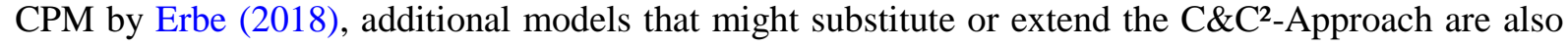
analysed. Thereby the following research questions are addressed:

- Which advantages and challenges emerge from the usage of elements and techniques of the $\mathrm{C} \& \mathrm{C}^{2}$-Approach in projects dealing with embodiment function relations?

- Which additional models are used in projects dealing with embodiment function relations and how are they related to the $\mathrm{C} \& \mathrm{C}^{2}$-Models?

\subsection{State of the art - the Contact and Channel Approach}

This section is based on Matthiesen et al. (2019b). Parts of the following text are taken from that paper without changes.

The $C \& C^{2}$-Approach is a thinking tool for embodiment design. Its aim is to support design engineers in recognizing function-related parameters of the embodiment. As a meta-model it contains elements and rules to build up explicit $\mathrm{C} \& \mathrm{C}^{2}$-Models. It consists of three key elements and three basic hypotheses that define the usage of its key elements. An overview of the three key elements Working Surface Pair (WSP), Channel and Support Structure (CSS) and Connector (C) is depicted in Figure 1. A WSP describes the interface where parts of the system connect while it fulfils its function. The CSS goes through system parts and connects the WSP. A CSS can include parts of components or whole subsystems depending to the modelling purpose. The Cs represent a model of the surrounding systems and transmit influences from outside the system boundaries into the system (Gladysz and Albers, 2018). The basic hypotheses describe possibilities and boundaries of the modelling with the ${\mathrm{C} \& \mathrm{C}^{2}-}^{-}$ Approach. They are depicted in Figure 1 (right side).

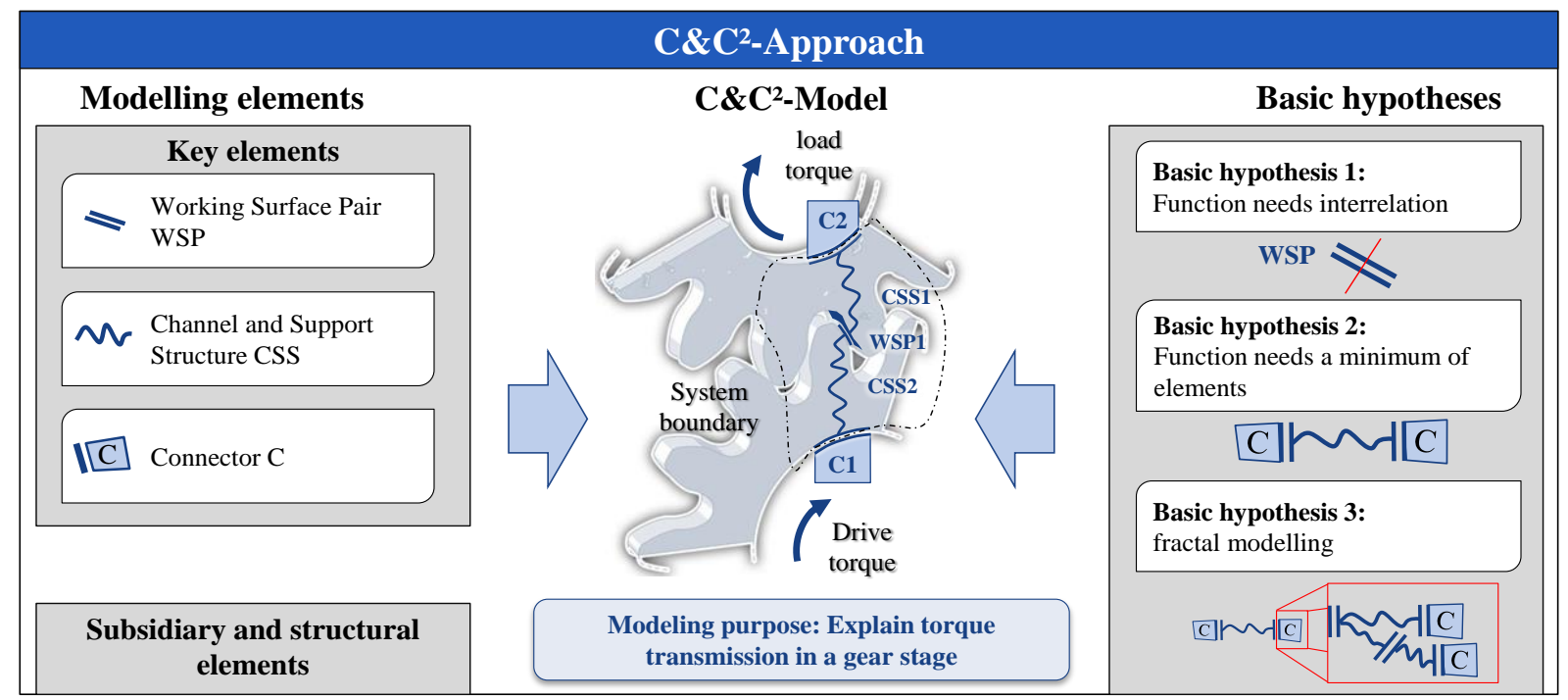

Figure 1. Overview of the $\mathrm{CAC}^{2}$-Approach and its elements (Matthiesen et al., 2018) 
A C\&C $\mathrm{C}^{2}$-Model (Figure 1, centre) is derived by using the key elements and basic hypotheses. For

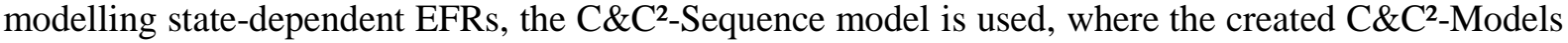
are structured according to their temporal sequence and also different levels of detail can be considered. (Matthiesen et al., 2019b)

For building up C\&C$C^{2}$-Models, the three techniques Zoom, Shift, and Change perspective exist. Zoom describes system analysis on different levels of detail. Shift is change of focus in system analysis on the same level of detail. Change perspective is system analysis of the same detail from different points of view. (Matthiesen, 2020)

\section{Materials and methods}

A survey on the usage of the $\mathrm{C} \& \mathrm{C}^{2}$-Approach and additional models for EFRs in research and development projects is conducted to answer the research questions. The survey is designed to gather

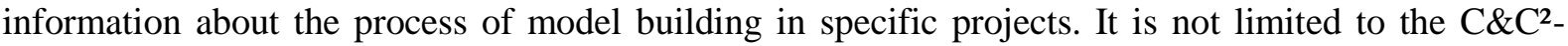
Approach but includes specific questions regarding elements and techniques of the approach. In the following sections, the selection of participants of the survey, the questionnaire design and the evaluation process are described.

\subsection{Target group of the survey}

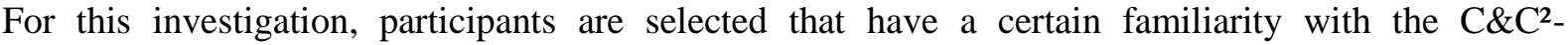
Approach. They should be able to use the approach, but its actual usage in modelling activities was not a requirement, as valuable insights are expected from researchers and practitioners that are familiar with the approach but did not use it. Researchers in product development who either work directly at the IPEK - Institute of Product Engineering, have worked there, or cooperate with it, have been asked to participate in the survey.

\subsection{Questionnaire design}

The questionnaire for the survey was built up to fit in the structure of established model building processes from literature. The chosen concept of the model building process was derived from the MoSim-Scheme by Günther and Velten (2014). They propose process steps for the building of mathematical models with the aim to answer a specific question about a system. Table 1 depicts the structure of the questionnaire with reference to the phases of the MoSim-Scheme.

Table 1. Structure of the questionnaire in accordance to the MoSim-Scheme by Günther and Velten (2014)

\begin{tabular}{|c|c|c|c|}
\hline $\begin{array}{l}\text { MoSim- } \\
\text { Scheme }\end{array}$ & Sections of questionnaire & Content of the sections & Evaluation \\
\hline \multirow[b]{2}{*}{ Definition } & Situation analysis & - Project key data & - Numbers / free text \\
\hline & Problem containment & $\begin{array}{l}\text { - Aim and focus of the project } \\
\text { - Initial modelling purposes }\end{array}$ & $\begin{array}{l}\text { - } \quad \text { Free text } \\
\text { - }\end{array}$ \\
\hline System analysis & Analysis & $\begin{array}{l}\text { - Analysis techniques } \\
\text { - Visualization basis }\end{array}$ & $\begin{array}{l}\text { - Likert scales / } \\
\text { free text }\end{array}$ \\
\hline $\begin{array}{l}\text { Modelling } \\
\text { Simulation }\end{array}$ & Model building & $\begin{array}{ll}\text { - } & \text { C\&C2-Modelling elements } \\
\text { - } & \text { Additional non-executable models } \\
\text { - } & \text { Additional executable models }\end{array}$ & $\begin{array}{l}\text { - Likert scales / } \\
\text { free text }\end{array}$ \\
\hline Validation & Verification / Validation & $\begin{array}{l}\text { - Formulation of hypotheses } \\
\text { - Testing of hypotheses }\end{array}$ & $\begin{array}{l}\text { - Checkbox / free } \\
\text { text }\end{array}$ \\
\hline & Model usage & $\begin{array}{l}\text { - Final modelling purposes } \\
\text { - Modelling results }\end{array}$ & $\begin{array}{l}\text { - Checkbox / free } \\
\text { text }\end{array}$ \\
\hline
\end{tabular}


The step Definition from the MoSim-Scheme is divided into two sections, Situation analysis and Problem containment. In the section Situation analysis, the participants give a short outline of the project. The duration of the project and team members involved in the project are asked and a free text answer about the circumstances all around the project could be given.

The section Problem containment analyses how the aim and focus of the project were set. Here also the modeling purposes are investigated. The given purposes in the checkboxes are divided into the five purposes 'capture the unknown', 'define the design', 'obtain insight', 'manage' and 'communicate' according to Andreasen et al. (2015). Examples for these purposes were given in the questionnaire e.g. 'build up a CAD model' for 'define the design' or 'structure information' for 'manage'.

In the sections Analysis and Model building, Likert scales are used to gather categorical data on the success criteria usefulness and applicability of Blessing and Chakrabarti (2009). For this, the participants were asked whether they deemed the element helpful (indicating usefulness) and if it was easy to use or not (indicating applicability). The rating of these criteria was done by five point Likert scales from strongly disagree to strongly agree with the neutral point of neither agree nor disagree. A free text box was available for explanation of the choices made.

In the section Analysis, techniques and models for the visualisation used in the system analysis phase are investigated. Regarding the techniques, specific answers are requested for the three techniques

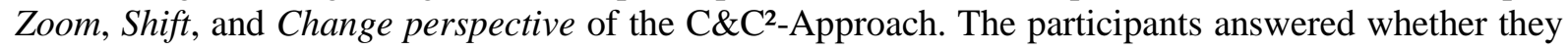
have used these techniques and if so, rated them with Likert scales. Additional analysis techniques could be added and rated as well if they were used. A dropdown template for Likert scale rating was provided. Regarding the models for visualisation the participants were asked to fill in which models they used and rate them similar to the techniques.

The section Model building is about the actual model building phase of the projects. Here, general questions about models built up and questions specific for elements of the $\mathrm{C} \& \mathrm{C}^{2}$-Approach were

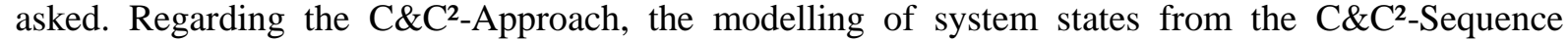
model, the key elements WSP, CSS and C (see also Figure 1) and the parameters in the key elements were rated and the choices explained. In the general questions, the participants were asked about which other models they used. The models are differentiated in non-executable models and executable models according to Sokolowski and Banks (2010). Examples for these models are also given, e.g. sketches being non-executable models and multibody simulations executable.

In the Verification and validation section, the focus is on the testing of the hypotheses that were developed through the model building phase. As verification and validation is a complex process which usually contains iterations and testing depending on the model (Sokolowski and Banks, 2010), only a short overview is investigated here. It is asked whether hypotheses were formulated and how testing was done.

In the Model usage as final section of the questionnaire, the participants are asked to categorize the purpose of the models according to Andreasen et al. (2015) again, now in retrospective of the projects outcome. The usage of the models built up in the project is investigated through whether a product concept was developed and/or a physical or virtual prototype was built up.

To sum up, the questionnaire contains three types of data:

- Quantitative data about the project types and which techniques and models were used in the projects.

- Categorical data from the Likert scales of the participants evaluation of usefulness and applicability.

- Qualitative data from the explanations of the evaluation and additional free text comments.

\subsection{Data evaluation}

To answer the research questions, all three types of data are evaluated. The quantitative data are used to classify the projects and the frequency of the model usage. The Likert scales are evaluated according to Robbins and Heiberger (2011) to give an overview of usefulness and applicability rating of the used models and techniques. The qualitative data from the participants' comments are evaluated by the authors following Delphi methods described by Okoli and Pawlowski (2004). In 
phase 1, brainstorming is done based on the collected comments. In phase 2, the comments are narrowed down into overarching statements if possible. In phase 3 , the consolidated comments from the preceding phase are ranked and integrated into the result section. The additional models are clustered by creating an overview of all models mentioned and then sorting the models to overarching terms which are described in section 3.2.

\section{Investigation results}

In total, from 29 contacted researchers, 17 participated in the survey. The 17 participants and returned 23 projects with full datasets of the survey. The project count was higher, as some participants were involved in more than one project. No incomplete datasets were returned. From the 23 investigated projects, 14 were bilateral development projects with industrial participants and 9 were research projects. The project duration ranged from three to 48 months (mean value 16 months, standard deviation 13.6). The active project team size reached from one (mean value 2.3 team members, standard deviation 1.6). In 20 of the 23 projects, $C \& C^{2}$-Models were built up. In three projects, the $\mathrm{C} \& \mathrm{C}^{2}$-Approach was not used by participants being familiar with it. These projects were included into the evaluation, as valuable insights about why it has not been used, were expected.

In $65 \%$ of the projects (15/23 cases) expert workshops or interviews were mentioned at the project kick-off. This was done in all bilateral projects and also in one research project where domain knowledge from industry was necessary. Figure 2 shows that in the investigated projects modelling was mostly used to obtain insight. However, all other purposes of Andreasen et al. (2015) were present as well.

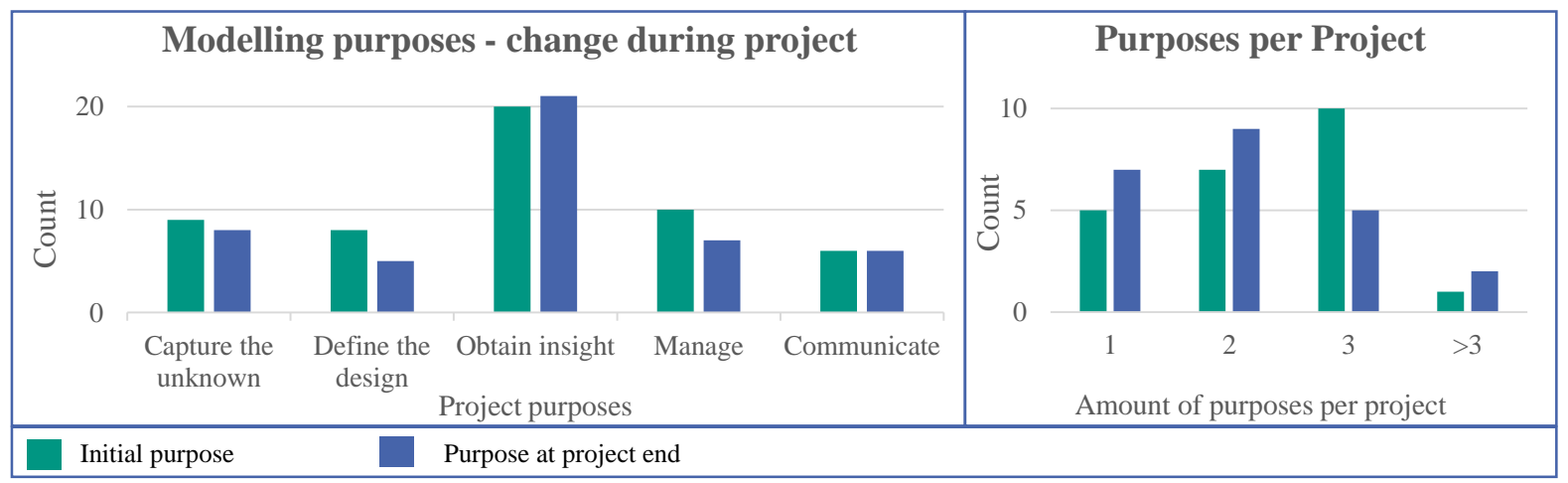

Figure 2. Comparison of initial purposes and purposes at project end

A shift towards 'obtain insight' is visible in Figure 2 left side. Initially more purposes per project (green bars in Figure 2, mean 2.3 per project) were aimed than purposes remain at the end of the projects (blue bars in Figure 2, mean 2.0 per project). At the beginning, most projects had three purposes, at the end, more projects had two or one purpose. This was somewhat expected as the objectives are usually sharpened during a project, narrowing its focus.

The model building projects led in $83 \%$ (19/23 cases) to formulation of hypotheses. In six cases, hypotheses were evaluated using virtual models and in 14 cases by using physical prototypes and experiments. In four projects, virtual and physical evaluation was applied. The amount of evaluated hypotheses was larger than the formulated hypotheses as some projects evaluated already existing hypotheses. In seven projects no evaluation took place. In model usage, 10 product concepts were developed, eight physical prototypes and six virtual prototypes.

\subsection{Investigating the C\&C ${ }^{2}$-Approach - database for research question 1}

In this section, the parts of the questionnaire regarding the $\mathrm{C} \& \mathrm{C}^{2}$-Approach are evaluated. In the analysis phase of the projects the three techniques of the $\mathrm{C} \& \mathrm{C}^{2}$-Approach are investigated. In Figure 3 , the results of the Likert scale evaluation are shown. 


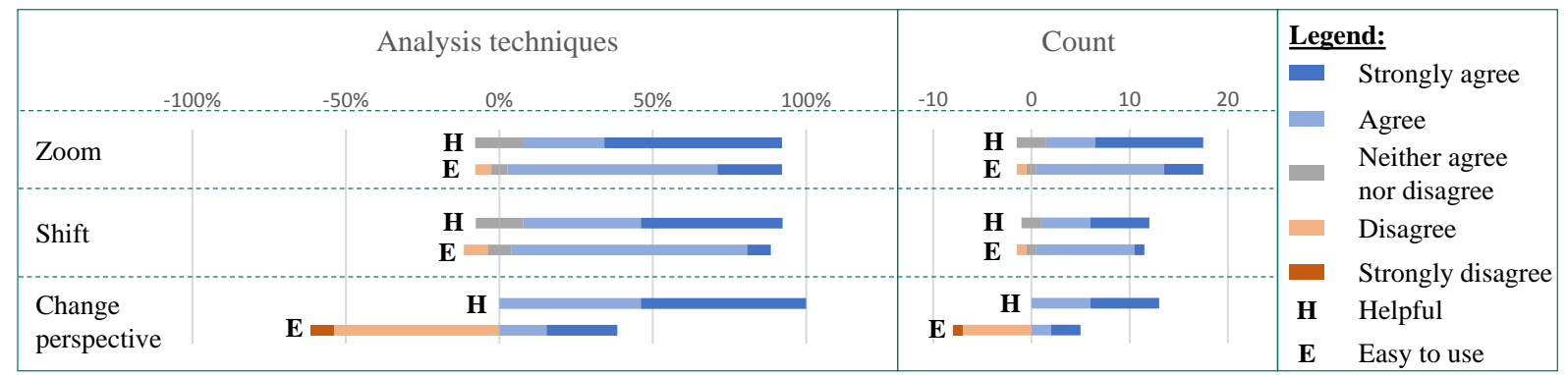

Figure 3. Analysis techniques for derivation of the depiction of the system

The technique Zoom was the most used technique in the projects (see count diagram, Figure 4). It was evaluated as helpful and easy to use. The comments show that it was used in two different ways. One was the investigation of technical drawings or CAD-models where a virtual zoom is done. The other was the investigation of a real system using microscopy. Shift was not used that often, but also evaluated as helpful and easy to use. Comments showed that it was often used in large systems where many system parts have to be investigated. Change perspective was evaluated as helpful, however it seemed difficult to use. Comments described it as helpful for dealing with 3D problems through dividing them down into different $2 \mathrm{D}$ views. Other comments mentioned extensive system preparation as a challenge. Sometimes the application was impossible in real systems and could only be done in the CAD-model of the system.

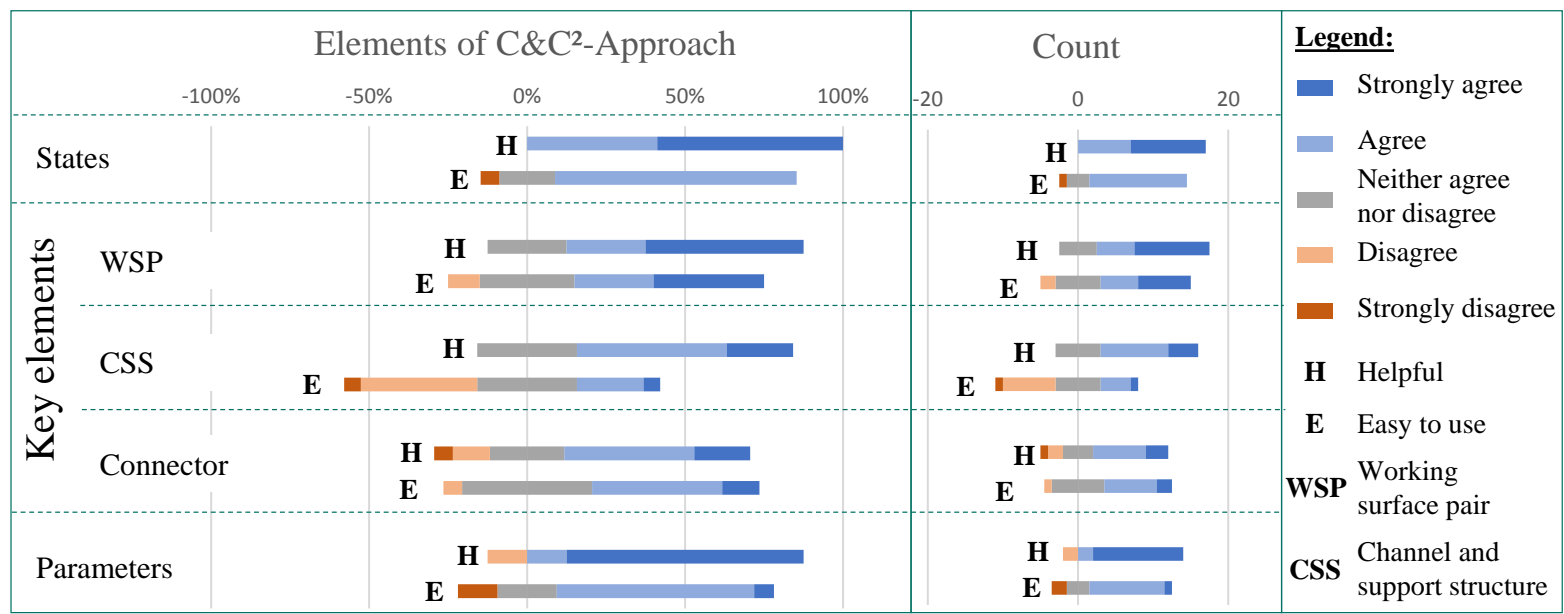

Figure 4. Evaluation of the elements of the $\mathrm{C \& C}^{2}$-Approach

Subsequently, in the model building phase, the elements of the $C \& C^{2}$-Approach are analysed. Figure 4 shows the results of their Likert scale evaluation.

Overall, only the element WSP was used in all 20 projects using $C \& C^{2}$-Models despite the definition of a C\&C ${ }^{2}$-Model consisting of WSPs, CSSs and Connectors. 19 projects applied CSSs, 17 Connectors and states, and 16 parameters. The missing elements were remarked as caused by pragmatic modelling, where for example only WSPs were in focus and a formally correct model was not deemed necessary. All of the used elements were rated as potentially helpful with ratings from $59 \%$ to $100 \%$ in the categories helpful and very helpful.

Modelling of the system states was considered very helpful and mostly easy to use, however a few cases showed extreme difficulties. Comments mostly regarded structuring of the system behaviour as helpful for identifying EFRs, e.g. through clustering of effects in videos of the real system in action. One comment was about the structural limitation of the $\mathrm{C} \& \mathrm{C}^{2}$-Sequence model that made basic research necessary to reach the projects aim.

The WSP was rated as the most helpful of the three key elements of the $C \& C^{2}$-Approach. Comments regarding challenges were about the difficulties in finding WSPs in real systems and displaying WSPs in $3 \mathrm{D}$ visualisations. CSSs were also rated as helpful, however a broad scatter was uncovered in how 
easy they were to use. In comments, they were regarded either as simple connections of WSPs or as extremely difficult to model, especially when a system failure was investigated. The connectors were rated in a broad spectrum in how helpful and easy to use they were. Comments were that often a connector contains only a force making it somewhat trivial or that many things engineers don't understand could be hidden in it.

Parameters were the least used elements of the $C \& C^{2}$-Approach. They were rated as the most helpful aspect of the $\mathrm{C} \& \mathrm{C}^{2}$-Approach and were also mentioned as basic for hypotheses and executable models based on the $\mathrm{C} \& \mathrm{C}^{2}$-Models. However, they are not part of the key elements and the missing standard in how to model them was mentioned as challenging. Two comments mentioned difficulties in finding and structuring them.

Based on this dataset, an evaluation of the first research question regarding advantages and challenges in the usage of elements and techniques of the $\mathrm{C} \& \mathrm{C}^{2}$-Approach in projects dealing with embodiment function relationships becomes possible. It is described in section 4 .

\subsection{Investigating additional models - database for research question 2}

In this section, the parts of the questionnaire regarding the usage of additional models in the investigated projects are evaluated. It is analysed which models and model building techniques are used and how they are related to the created $C \& C^{2}$-Models. In sum, 84 additional models were used in the 23 projects.

Difficulties emerged in assigning them to the predefined categories. The participants had different understandings of assigning their models to the categories analysis technique, visualisation, nonexecutable models and executable models (see also Table 1). Therefore the authors collected all mentioned additional models and clustered them by grouping them and assigning overarching terms to the groups. The mentioned models and overarching terms are described in Table 2 as follows:

Table 2. Description of clusters used for model analysis

\begin{tabular}{|c|c|c|}
\hline $\begin{array}{l}\text { Overarching } \\
\text { terms }\end{array}$ & $\begin{array}{l}\text { Description } \\
\text { of the terms }\end{array}$ & $\begin{array}{c}\text { Mentioned models } \\
\text { (number of cases mentioned) }\end{array}$ \\
\hline MBSE & $\begin{array}{l}\text { Models for system description } \\
\text { based on MBSE principles }\end{array}$ & $\begin{array}{l}\text { SysML (2), internal block diagramm (1), block definition } \\
\text { diagramm (1) }\end{array}$ \\
\hline Measurements & Models of system behaviour & $\begin{array}{l}\text { Measurements (4), regression model (2), DoE (1), torque } \\
\text { characteristic (1), measuring data (1) }\end{array}$ \\
\hline Simulations & $\begin{array}{l}\text { Executable mathematical } \\
\text { description of system behaviour }\end{array}$ & Multibody simulation (8), Calculations (4), FEM simulation (3) \\
\hline $\begin{array}{l}\text { Graphical } \\
\text { models }\end{array}$ & $\begin{array}{l}\text { Models that define the product } \\
\text { geometry }\end{array}$ & $\begin{array}{l}\text { CAD (23), sketches (8), technical drawings (5), model of } \\
\text { Mattheck (1), geometric relations (1) }\end{array}$ \\
\hline Observation & $\begin{array}{l}\text { Models used to observe the } \\
\text { behaviour of the real system }\end{array}$ & $\begin{array}{l}\text { Intersections (3), photos (3), highspeed-videos (2), cut model (1), } \\
\text { abrasion analysis (2), video-based models ( } 2 \text { ) }\end{array}$ \\
\hline $\begin{array}{l}\text { System } \\
\text { analysis tools }\end{array}$ & $\begin{array}{l}\text { Models for structural analysis of } \\
\text { technical systems }\end{array}$ & $\begin{array}{l}\text { Function tree (3), Ishikawa-diagram (1), FMEA (1), FTA (1), } \\
\text { Parameter mindmap (1) }\end{array}$ \\
\hline Prototypes & $\begin{array}{l}\text { Physical models of the product or } \\
\text { its aspects }\end{array}$ & $\begin{array}{l}\text { Prototypes (6), real system parts (5), 2D prototypes (2), reference } \\
\text { system (1) }\end{array}$ \\
\hline
\end{tabular}

Legend: $M B S E=$ Model-based systems engineering; DoE = Design of experiments; $F E M=$ Finite element model; $C A D$

= Computer-aided design; FMEA = Failure mode and effects analysis; FTA = Fault tree analysis;

The clustered models were analysed using the Likert scale. The used models differed depending on the system and model purpose. Observations, simulations and prototypes were used for investigation of real system behaviour, but they were considered as hard to use as most of these tools needed highly sophisticated equipment like high-speed cameras or 3D microscopy. The usage of simulations, especially in combination with measurements, was considered helpful, however comments described that these approaches require expert knowledge and necessitate much effort. These results are shown in Figure 5. 


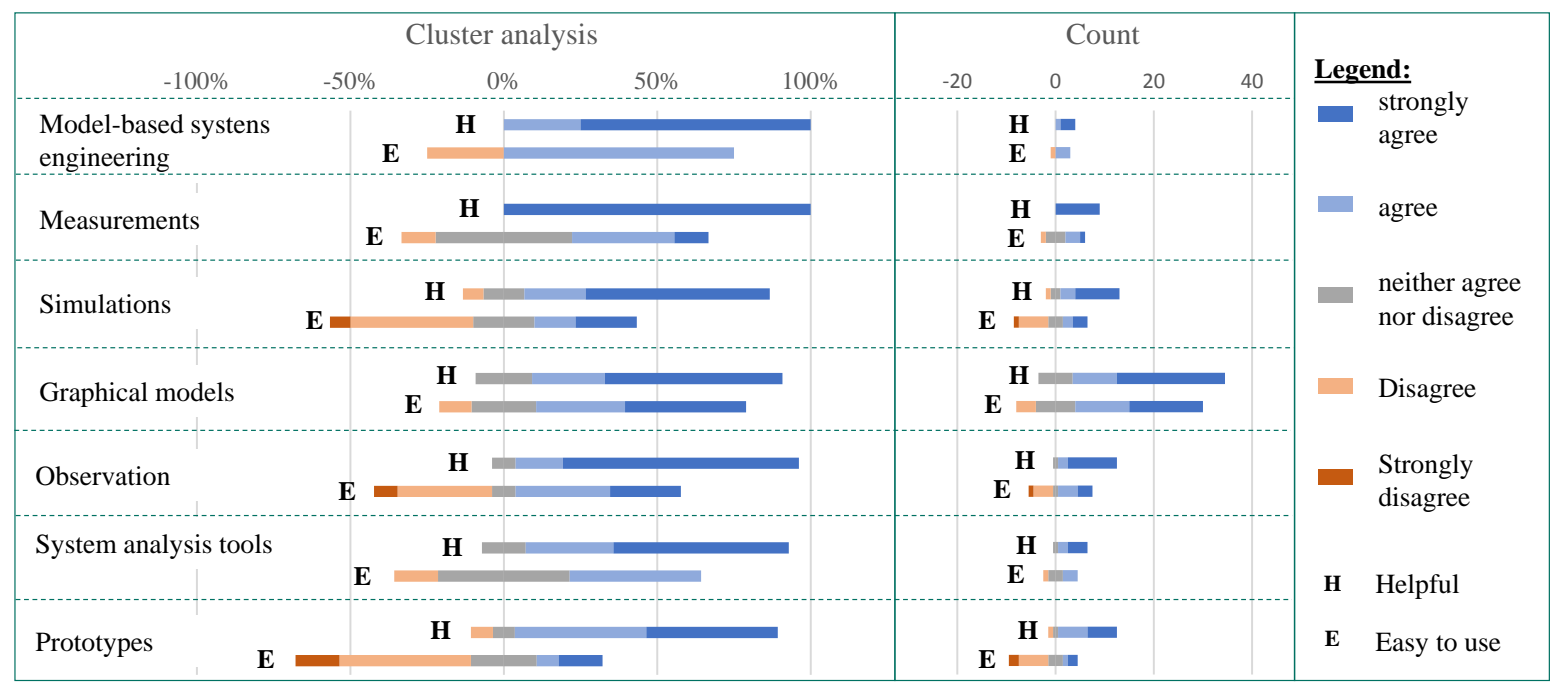

Figure 5. Additional models used in the projects

The investigation results show that usually other models were used besides the $C \& C^{2}$-Approach. Therefore, the dataset was evaluated by the authors for mentioned connections between models in the clusters and the $\mathrm{C} \& \mathrm{C}^{2}$-Approach. The results are shown in Table 3.

Table 3. Connection of the model clusters to the C\&C2-Approach

\begin{tabular}{lrrrrrr}
\hline Model cluster & \multicolumn{1}{c}{ Connection mentioned } & \multicolumn{2}{c}{ no connection } & \multicolumn{2}{c}{ unclear } \\
\hline Model-based systems engineering & $50.0 \%$ & $(2 / 4)$ & $0.0 \%$ & $(0 / 4)$ & $50.0 \%$ & $(2 / 4)$ \\
\hline Measurement & $10.0 \%$ & $(1 / 10)$ & $20.0 \%$ & $(2 / 10)$ & $70.0 \%$ & $(7 / 10)$ \\
\hline Simulation & $20.0 \%$ & $(3 / 15)$ & $40.0 \%$ & $(6 / 15)$ & $40.0 \%$ & $(6 / 15)$ \\
\hline Graphical models & $65.7 \%$ & $(23 / 35)$ & $2.9 \%$ & $(1 / 35)$ & $31.4 \%$ & $(11 / 35)$ \\
\hline Observation & $71.4 \%$ & $(10 / 14)$ & $0.0 \%$ & $(0 / 14)$ & $28.6 \%$ & $(4 / 14)$ \\
\hline System analysis tools & $61.5 \%$ & $(8 / 13)$ & $23.1 \%$ & $(3 / 13)$ & $15.4 \%$ & $(2 / 13)$ \\
\hline Prototype & $66.7 \%$ & $(10 / 15)$ & $6.7 \%$ & $(1 / 15)$ & $26.7 \%$ & $(4 / 15)$ \\
\hline
\end{tabular}

In $50 \%$ of the projects using MBSE models, a connection to $\mathrm{C} \& \mathrm{C}^{2}$-Approach was mentioned. Comments described $\mathrm{C} \& \mathrm{C}^{2}$-Models as useful to support modelling of interactions at system boundaries.

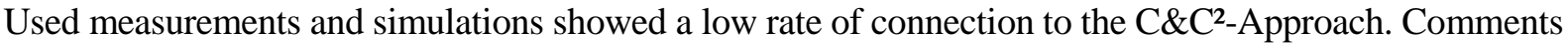
remarked missing compatibility. Measurements were often used later in the projects, where e.g. test benches already existed and the $\mathrm{C} \& \mathrm{C}^{2}$-Models were no longer used. Graphical models, observations, system analysis tools and prototypes were used mostly connected to the $\mathrm{C} \& \mathrm{C}^{2}$-Approach. Comments showed that graphical models were necessary to build C\&C $\mathrm{C}^{2}$-Models, especially CAD was often used as basis for simple and fast visualisations. Graphical models were also useful for the depiction of system observations and the understanding of system behaviour. Other comments described that ${\mathrm{C} \& \mathrm{C}^{2} \text {-Models }}^{2}$ were difficult to use for $3 \mathrm{D}$ problems. The system analysis tools were also often connected to the $\mathrm{C}_{2} \mathrm{C}^{2}-$ Approach. Comments showed that a combination with $C \& C^{2}$-Models was helpful to structure the system

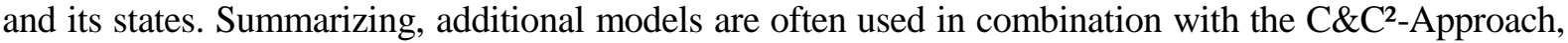
however quantitative models are seldom connected to it. In some cases it remained unclear whether there was a connection of other models with the $\mathrm{C} \& \mathrm{C}^{2}$-Approach.

\section{Discussion}

Based on the results of section 3.1, the first research question concerning advantages and challenges of the $C \& C^{2}$-Approach in its application in projects can be answered as follows: Advantages are shown regarding applicability, as the elements of the $C \& C^{2}$-Approach are evaluated as relatively easy to use. 
The elements as well as the techniques of the $C \& C^{2}$-Approach are evaluated regarding their usefulness as mostly helpful. Especially the techniques zoom and shift are rated and commented as very helpful and easy to use. Zoom is mentioned as very intuitive. Shift is mentioned as helpful in the analysis of large and complicated systems. Change perspective is mentioned as very useful to identify unknown EFRs in 3D systems. These results indicate most elements of the $\mathrm{C} \& \mathrm{C}^{2}$-Approach as an easy to use modelling approach that can support in projects dealing with EFRs. Challenges emerge in how to model different cases and when to apply which elements of the $C \& C^{2}$-Approach. Sometimes elements are modelled just for formal causes. Regarding the CSSs, comments range from very helpful to 'it is just used to connect WSPs'. Difficulties are mentioned in how to draw the power flow through the system and how to model the CSSs in a supportive way. This indicates a lack of support in how to use CSSs. The connectors are often only used for formal reasons indicating that the participants had difficulties using them according to their purpose. This might be caused by a lack of training as the Connectors are taught since 2013, where most of the participants had already finished the basic

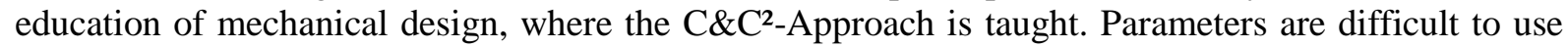
as no formal way of modelling them exists in the $C \& C^{2}$-Approach. The technique change perspective is rated as very difficult to use especially in real systems, where sophisticated equipment is necessary and sometimes its application was impossible. These results indicate the need for support in how to use the $\mathrm{C} \& \mathrm{C}^{2}$-Approach and formal integration of parameters into it.

Based on the results of section 3.2, the second research question about the usage of additional models and their relation to $\mathrm{C} \& \mathrm{C}^{2}$-Models can be answered as follows: A large variety of models is used in addition to the $\mathrm{C} \& \mathrm{C}^{2}$-Models of which almost all are rated as helpful. Regarding the rating of how easy they are to use, differences between the clusters are shown, as e.g. product definition models are mostly rated as easy to use, while prototypes, calculations/simulation and system observation are at least partially very difficult to use. However, these models are often used to obtain insight despite the effort required. The most used models are the graphical models with focus on CAD indicating them as basis for projects investigating EFRs. CAD is often used for simple and fast visualisations besides the obvious usage as basis for real system prototypes that need a 3D CAD model for manufacturing. Real systems or prototypes are used for visualisation of the details and real behaviour (measurements, prototypes, observations) in addition to the CAD models. In five of the seven clusters, 50\% or more of the models are connected to the $C \& C^{2}$-Approach. The highest rate is shown in system observation, where almost 3/4 of the models are used to provide a visualisation basis for the $\mathrm{C} \& \mathrm{C}^{2}$-Approach. Prototypes are also often related to the $C \& C^{2}$-Approach, partly as visualisation basis and partly synthesized from the $C_{\&} \& C^{2}$ Models for testing of hypotheses. Quantitative models like measurements or calculation/simulation are seldom linked to the $\mathrm{C} \& \mathrm{C}^{2}$-Models. They are used to quantify EFRs and need parameters as input. This link is difficult to establish as parameters are not yet formally integrated into the $\mathrm{C} \& \mathrm{C}^{2}$-Approach.

The study design as a survey study enabled identification of up to now unknown research potential of the $\mathrm{C} \& \mathrm{C}^{2}$-Approach. It might therefore also support in investigating other modelling approaches in design engineering. Limitations regarding the investigation are the retrospective analysis and the focus of the projects on EFRs. The retrospective limitations emerge from the long project duration, where details of modelling might have been forgotten by the project workers. Also more than one project worker was involved in almost all projects, however the data was collected by asking one of the project members. The investigation does not cover typical industrial product development but only the parts where companies are in need of research for product development and consult research institutions.

\section{Conclusion and outlook}

Aim of this investigation was to identify advantages and challenges of the $C \& C^{2}$-Approach as well as the

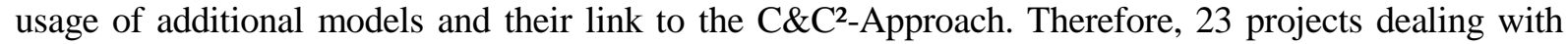
embodiment function relations were analysed through a survey study. The results show advantages of the $\mathrm{C} \& \mathrm{C}^{2}$-Approach regarding its applicability and usefulness. Challenges are identified regarding applicability of the elements CSS and Connector and the integration of parameters. These challenges can be used as basis for further research to improve applicability and usefulness of the $C_{\&} \& \mathrm{C}^{2}$-Approach. Many additional models are used to enable modelling with the $C \& C^{2}$-Approach or are synthesized from the $C \& C^{2}$-Models. However, quantitative models seem difficult to link to the $C \& C^{2}$-Approach. For a 
coherent model usage in modelling projects, further research into integration of parameters into the $\mathrm{C} \& \mathrm{C}^{2}$-Approach is necessary to improve combined usage with quantitative models like simulations or tolerance analyses.

\section{References}

Albers, A. and Matthiesen, S. (2002), "Konstruktionsmethodisches Grundmodell zum Zusammenhang von Gestalt und Funktion technischer Systeme", in Konstruktion - Zeitschrift für Produktentwicklung und Ingenieur-Werkstoffe, Vol. 54, Springer-VDI-Verlag, Düsseldorf, pp. 55-60.

Andreasen, M.M., Hansen, C.T. and Cash, P. (2015), Conceptual Design: Interpretations, Mindset and Models, Springer International Publishing, Cham, Switzerland.

Blessing, L.T.M. and Chakrabarti, A. (2009), DRM, a design research methodology, Springer, Dordrecht.

Buur, J. and Andreasen, M.M. (1989), "Design models in mechatronic product development", Design Studies, Vol. 10 No. 3, pp. 155-162.

Ehrlenspiel, K. and Meerkamm, H. (2017), Integrierte Produktentwicklung: Denkabläufe, Methodeneinsatz, Zusammenarbeit, 6th edition, Carl Hanser Verlag GmbH \& Co. KG, München, Wien.

Erbe, T. (2018), "CPM-Modeling in industry - a reflection”, in 29. DFX-Symposium 2018, Tutzing, Germany.

Gladysz, B. and Albers, A. (2018), "How Do C\&C²-Models Improve Efficiency, Comprehensibility and Scope In Failure Analysis - an Empirical Study Based on Two Live-Labs", in 16th International Design Conference DESIGN, Dubrovnik, Croatia.

Grauberger, P. et al. (2019), "The contact and channel approach - 20 years of application experience in product engineering", Journal of Engineering Design. https://dx.doi.org/10.1080/09544828.2019.1699035

Günther, M. and Velten, K. (2014), Mathematische Modellbildung und Simulation Eine Einführung für Wissenschaftler, Ingenieure und Ökonomen, John Wiley \& Sons, Incorporated, Berlin, Germany.

Haefner, B. and Lanza, G. (2017), "Function-oriented measurements and uncertainty evaluation of micro-gears for lifetime prognosis", CIRP Annals, Vol. 66 No. 1, pp. 475-478.

Kohn, A. (2014), "Entwicklung einer Wissensbasis für die Arbeit mit Produktmodellen”, Dissertation, Lehrstuhl für Produktentwicklung, Technische Universität München, München, Germany.

Matthiesen, S. (2002), "Ein Beitrag zur Basisdefinition des Elementmodells "Wirkflächenpaare \& Leitstützstrukturen' zum Zusammenhang von Funktion und Gestalt technischer Systeme”, Dissertation, University of Karlsruhe (TH), Karlsruhe, Germany.

Matthiesen, S. (2011), "Seven Years of Product Development in Industry - Experiences and Requirements for Supporting Engineering Design with 'Thinking Tools", in 18th International Conference on Engineering Design, Copenhagen, Denmark.

Matthiesen, S. (2020), "Prozess und Methoden der Gestaltung", in Bender, B. and Gericke, K. (Eds.), Pahl/Beitz Konstruktionslehre, 9th ed., Springer-Verlag GmbH. Berlin Heidelberg, Germany. In print.

Matthiesen, S. et al. (2019a), "Product Models in Embodiment Design - An Investigation of Challenges and Opportunities", Springer Nature Applied Sciences, No. 1, p. 1078.

Matthiesen, S., Grauberger, P. and Schrempp, L. (2019b), "Extended Sequence Modelling in Design Engineering Gaining and Documenting Knowledge about Embodiment Function Relations with the C\&C ${ }^{2}$-Approach", in 22nd International Conference on Engineering Design ICED19, Delft, The Netherlands.

Matthiesen, S. et al. (2018), "From Reality to Simulation - Using the C\&C²-Approach to Support the Modelling of a Dynamic System", in Procedia CIRP, Vol. 70, pp. 475-480.

Okoli, C. and Pawlowski, S.D. (2004), "The Delphi method as a research tool: an example, design considerations and applications", Information \& Management, Vol. 42 No. 1, pp. 15-29.

Robbins, N. and Heiberger, R. (2011), "Plotting Likert and other rating scales", in Proceedings of the 2011 Joint Statistical, Miami, USA, pp. 1058-1066.

Sokolowski, J.A. and Banks, C.M. (2010), Modeling and Simulation Fundamentals, John Wiley \& Sons, Inc., Hoboken, NJ, USA.

Stachowiak, H. (1973), Allgemeine Modelltheorie, Springer, Wien, New York.

Suh, N.P. (1998), “Axiomatic Design Theory for Systems”, Res Eng Des, Vol. 10 No. 4, pp. 189-209.

Wagner, R., Haefner, B. and Lanza, G. (2018), "Function-Oriented Quality Control Strategies for High Precision Products", Procedia CIRP, Vol. 75, pp. 57-62.

Weber, C. (2014), "Modelling Products and Product Development Based on Characteristics and Properties", in Chakrabarti, A. and Blessing, L.T.M. (Eds.), An Anthology of Theories and Models of Design: Philosophy, Approaches and Empirical Explorations, Springer, London, United Kingdom, pp. 327-352.

Yassine, A. and Braha, D. (2003), "Complex Concurrent Engineering and the Design Structure Matrix Method", Concurrent Engineering, Vol. 11 No. 3, pp. 165-176. 